\title{
Physiological and Behavioral Effects of d-threo-methylphenidate Hydrochloride in Male Wistar-Kyoto and Spontaneously Hypertensive Rats
}

\author{
Jennifer Lee Sayler, Linda Tennison, and David Mitchell \\ College of Saint Benedict and Saint John's University \\ St. Joseph, Minnesota 56374 USA
}

Received: May 15, $2002 \quad$ Accepted: June 5, 2003

\begin{abstract}
Millions of children and adults worldwide are diagnosed with Attention-deficit hyperactivity disorder (ADHD) and yet its very existence, definition, and treatment are surrounded with discord and controversy. ADHD and its treatments are brought together through this investigation into the effects that drug therapy has on Wistar Kyoto rats (WKY) and a strain of Spontaneously Hypertensive rats (SHR) selectively inbred from WKY rats. The effects of the drug d-threomethylphenidate hydrochloride (d-MPH - the d-isomer of the ADHD drug Ritalin $\AA$ ) on spatial working memory abilities, overall growth rate, blood glucose levels, blood $\mathrm{pH}$, and erythrocyte membrane lipids were examined in the two rat strains. Although all four physiological properties remained constant and normal over the course of the experiment, the spatial working memory abilities were inhibited in WKY rats receiving the drug. These results suggest that the d-isomer of this drug may have a significant impact on cognitive function in rats and possibly humans.
\end{abstract}

\section{INTRODUCTION}

The National Institute of Mental Health (NIMH) offers the definition that Attention-deficit hyperactivity disorder (ADHD) is "a family of related chronic, neurobiological disorders that interfere with an individual's capacity to regulate activity level, inhibit behavior, and attend to tasks in developmentally appropriate ways (NIMH, 2000)."[1] The ruling guidebook for the definition and diagnosis of currently accepted mental illnesses is the Diagnostic and Statistical Manual of Mental Disorders [2]. According to this manual, ADHD "is a persistent pattern of inattention and/or hyperactivity-impulsivity that is more frequently displayed and more severe than is typically observed in individuals at a comparable level of development" (DSM-IV). Symptoms must be present before the age of seven in two or more different environments and cannot be the result of another disorder. In the United States $7.5 \%$ of school age children are suspected of having ADHD [3].

As to a cause of ADHD, the dopamine hypothesis suggests that ADHD is due to a hypofunctioning meso-limbic dopamine system, which results in low levels of the neurotransmitter dopamine in the brain [4]. This statement was made after the demonstration that amphetamines reduced hyperactivity in rats that were dopamine depleted by the neurotoxin 6hydroxydopamine or 6-OHDA [4]. Another interesting characteristic of the brain in human adults diagnosed with ADHD is a lower level brain blood glucose levels [5].

In 1961, the Food and Drug Administration approved d/l-threomethylphenidate hydrochloride (MPH), under the brand name of Ritalin $\AA$, to treat people with behavior problems. The manufacturer of Ritalin ${ }^{\circledR}$ (a class II controlled substance), Novartis 
Pharmaceuticals Corporation, classifies it as a mild central nervous system stimulant and it has become the most well known treatment of ADHD. In fact, $90 \%$ of all children who are prescribed stimulant medication to treat ADHD are prescribed Ritalin ${ }^{\circledR}$ [6]. In 1975, 150,000 children were taking this drug, but by the year 2000 nearly one in eight American children were taking Ritalin $\circledast$. The increased prevalence of this drug has raised questions and concerns as to its validity, safety and overall purpose.

$\mathrm{MPH}$ promotes catecholamine release and acts as a dopamine agonist that raises levels of dopamine in the cerebral cortex and thalamus by blocking the autoreceptors that reabsorb dopamine in the synaptic cleft. As a result, dopamine travels through the reward circuit of the brain more efficiently causing an individual to feel stimulated and thus content. A typical dose given to children is $0.5 \mathrm{mg} / \mathrm{kg}$ and this amount has been found to block up to $70 \%$ of the available dopamine auto receptors [7]. Depending upon the individual, this level of blockage may be sufficient to allow adequate neurotransmitter stimulation. The effective dosage depends upon each individual and on the severity of the disorder. The severity is believed to be a due to the overall number of auto receptors and level of dopamine in the limbic system.

This experiment included six male spontaneously hypertensive rats (SHR) and six male Wistar-Kyoto (WKY) rats as animal models for examining the physiological and behavioral effects of d-threomethylphenidate hydrochloride (d-MPH) the common ADHD drug Ritalin $\AA$ is a mixture of the $d$ and I isomers. The SHR rats are selectively inbred from progenitor Wistar-Kyoto rats and are most frequently used as an ADHD model [4]. Researchers have concluded that SHR rats are a valid animal model of ADHD because the behavior of these animals mimics the fundamental behavioral symptoms of ADHD. These symptoms include motor impulsiveness and over-activity that develop over time, cognitive impulsiveness, increased behavioral variability and a deficient response re-engagement [4].

This experiment was designed to select and examine specific characteristics that may be variable due to methylphenidate administration. Such variables included spatial working memory, blood glucose and $\mathrm{pH}$ levels, growth rate, and erythrocyte membrane lipids. Overall, the SHR rats that received the drug were expected to perform better on the behavioral tasks examining spatial working memory ability than the SHR rats receiving the placebo. Conversely, the WKY rats were expected to perform more poorly when receiving the drug. Due to the fact that a possible side effect listed for this drug is inhibition of appetite physiological parameters (growth rate, blood glucose levels, blood $\mathrm{pH}$ ) were tested. The growth rate was expected to be hindered while the rats received the drug and blood glucose and $\mathrm{pH}$ were expected to remain steady. Blood lipid levels were checked as a possible indicator of changes in cell membrane structure and function and were expected to remain stable throughout the experiment.

\section{MATERIALS AND METHODS}

The basic experimental procedure is outlined in Table 1. The SHR and WKY rat strains were purchased from Taconic Corporation (Germantown, NY). To establish the initial physiological and behavioral readings, a total of 100-200 micro liters of blood was drawn from each rat via a needle prick from the saphenous vein and collected with a capillary tube two days before the beginning of drug administration. This blood was used to measure their initial blood glucose levels, blood $\mathrm{pH}$ and blood lipid composition. The initial weight of each rat was recorded and measured every day for each rat before drug administration to determine proper drug dosage and overall growth rate throughout the experiment.

The experimental period began once the rats reached 41 days of age. At this point they were large enough to administer intraperitoneal injections and draw blood from the saphenous vein. Three males from each strain (SHR 4-6 and WKY 7-9) served as the initial control group and were administered intraperitoneal shots of sterile saline every test day. The remaining three males from each strain (SHR 1-3 and WKY 10-12) were given intraperitoneal injections of saline mixed with five milligrams of d-MPH per kilogram of body weight and served as the test group. Five milligrams per kilogram was a low 


\begin{tabular}{|c|c|c|c|c|c|}
\hline $\begin{array}{l}\text { Experiment } \\
\text { Phases }\end{array}$ & $\begin{array}{c}\text { SHR } \\
\text { group 1 } \\
\text { (Rats 1-3) }\end{array}$ & $\begin{array}{c}\text { SHR } \\
\text { group 2 } \\
\text { (Rats 4-6) }\end{array}$ & $\begin{array}{c}\text { WKY } \\
\text { group 1 } \\
\text { (Rats 7-9) }\end{array}$ & $\begin{array}{c}\text { WKY } \\
\text { group 2 } \\
\text { (Rats 10-12) }\end{array}$ & $\begin{array}{l}\text { Testing } \\
\text { Conducted }\end{array}$ \\
\hline Pre-experimental & - & - & - & - & $\begin{array}{l}\text { Weight recorded for } \\
13 \text { consecutive } \\
\text { days prior to } \\
\text { beginning of } \\
\text { experiment to } \\
\text { establish initial } \\
\text { growth curve } \\
\text { Initial blood glucose } \\
\text { lipid composition, } \\
\text { and pH levels } \\
\text { measured }\end{array}$ \\
\hline $\begin{array}{l}\text { Testing Period I } \\
\text { (Days 1-12) }\end{array}$ & Drug & Placebo & Placebo & Drug & $\begin{array}{ll}\text { - } & \text { Drug/placebo } \\
\text { administered every } \\
\text { day } \\
\text { - } \quad \text { Weight measured } \\
\text { every day } \\
\text { - Blood drawn and } \\
\text { tested for pH, lipid } \\
\text { composition, and } \\
\text { glucose levels } \\
\text { intermittently } \\
\text { (approx every } 3^{\text {rd }} \\
\text { day) } \\
\text { Maze test run } \\
\text { testing days 5-12. } \\
\end{array}$ \\
\hline $\begin{array}{l}\text { Testing Period II } \\
\text { (Days 13-24) }\end{array}$ & Placebo & Drug & Drug & Placebo & $\begin{array}{l}\text { Drug/placebo } \\
\text { administered every } \\
\text { day } \\
\text { Weight measured } \\
\text { every day } \\
\text { Blood drawn and } \\
\text { tested for pH, lipid } \\
\text { composition, and } \\
\text { glucose levels } \\
\text { intermittently } \\
\text { (approx every } 3^{\text {rd }} \\
\text { day) } \\
\text { Maze test run } \\
\text { testing days } 17-24 \text {. }\end{array}$ \\
\hline
\end{tabular}

Table 1. Experimental Design

dosage that had been shown to influence different learning and behavior patterns in previous studies $[8,9]$. This dosage is also ten times less potent than the established toxicity level of $50 \mathrm{mg} / \mathrm{kg}$ delivered to rats intravenously (DSM-IV). Beginning with the thirteenth experiment day, the assignment of the drug and the placebo was inverted with SHR 4-6 and WKY 7-9 received the drug and SHR 1-3 and WKY 10-12 received the placebo. This was completed to examine the effects of the drug on all rats involved.
All tests were run identically with the administration of the drug being the only experimental condition changed.

Each rat was tested individually to determine its ability to complete the Morris water maze [10]. This maze was simply a large circular container approximately 2 meters in diameter and 2/3 meter deep. A small platform approximately 25 centimeters high and 20 centimeters in diameter was placed in the tub in the same location each day of the test. The tub was filled with warm 
water until the level was approximately $2 / 3$ of a centimeter above the platform. Non-fat dry milk was added to make the water opaque concealing the platform from the swimming rats. The rats were placed in the same location of the tub every day and swam in search of an opportunity to remove themselves from the water. Once they learned that a platform was present in the tub, they memorized and swam to the platform as quickly as possible due to their inherent distaste for being immersed in water. Because the platform was visually undetectable to the rats, they had to orient themselves according to objects in the room to remember the platform's location. The amount of time until the rat found the platform was recorded. If necessary and to avoid exhaustion, the rats were removed from the water and placed on the platform if they swam for 60 consecutive seconds without finding the platform. The rats were allowed to rest on the platform for ten seconds in between testing sessions. The maze test was run three consecutive times each day for each rat the fifth through the twelfth and the seventeenth through the twenty-fourth days of the experiment. The results were compiled and evaluated using the Statistical Package for the Social Sciences software program (SPSS).

To examine certain physiological effects of the drug on the rats, blood glucose levels, blood $\mathrm{pH}$, and blood lipid composition were measured throughout the testing period. Blood draws occurred in the evening approximately 8 hours after the morning drug administration. Blood glucose levels were determined using an ACCU-Check Instant glucose meter manufactured by Rouche Diagnostics. Blood lipid testing involved the separation of red blood cells from plasma and thin layer chromatography experiments that included phosphatidyl serine, phosphatidyl choline, and phosphatidyl ethanolamine as positive controls [11]. Phosphatidyl serine is a phospholipid essential to the structure and function of brain cells [12].

Each injection was administered at the same time each morning to ensure consistency in scheduling. Only one rat was removed from its cage at a time to ensure that the data was specific to each test subject. Separate handling of the rats was important, as all rats were not easily distinguishable. The rats were placed into four experimental groups (Table 1). SHRs 1-3 were in a group and were placed under the same experimental condition regarding drug or placebo administration. The same followed for SHRs 4-6, WKYs 7-9 and the WKYs 10-12. SHRs 1-3 and WKYs 10-12 were arbitrarily assigned to receive the drug for the first experimental period while SHRs 4-6 and WKYs 7-9 received the drug during the second period.

\section{RESULTS AND DISCUSSION}

\section{a. Behavior}

The overall behavioral data was examined to determine the presence of a learning curve, the effects of receiving the drug and then the placebo on maze performance, the effects of receiving the placebo and then the drug on maze performance, and the basic differences in performance between the two strains. All comparisons were made by examining the means as well as the standard deviations across the trials using the Statistical Package for the Social Sciences software program (SPSS).

An important factor when interpreting the results of the Morris water maze is the presence of a learning curve over the course of the testing period for all rats. There was a significant $(\underline{F}(15,150)$ $=23.67, \mathrm{p}<0.0001)$ negative slope over the total days of maze testing for mean time to complete the maze. There was also a reduction in the variability of performance seen by examining the standard deviations of the individual times $(\underline{F}(15,150)=9.215$, $\mathrm{p}=0.0001$ ). Interpretation of these results show that the rats succeeded in learning the task during the experiment in that they began to complete the maze faster and more consistently over the trials.

The second most noticeable pattern is that the WKY rats completed the maze more slowly than the SHRs (Figure 2). Overall, there is a clear difference in the basic spatial working memory capabilities of SHR versus $W K Y$ rats $(\underline{F}(1,10)=8.13$, $\mathrm{p}=0.017)$. While the WKY rats were slower with completing the task, it is important to emphasize that the both the SHR and WKY strains learned the maze at the same rate. 
Average time per day to Morris Water Maze completion for SHR 1-3

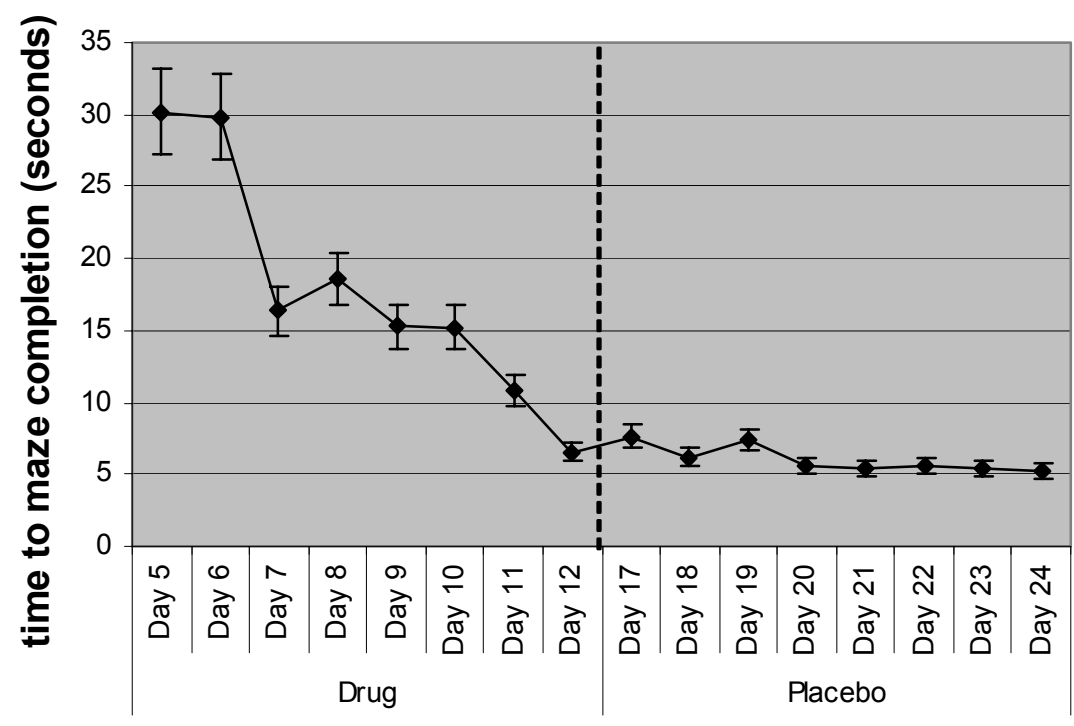
$\longrightarrow$ Average Time -
SHR\#1-3

Average time per day to Morris Water Maze completion for SHR 4-6
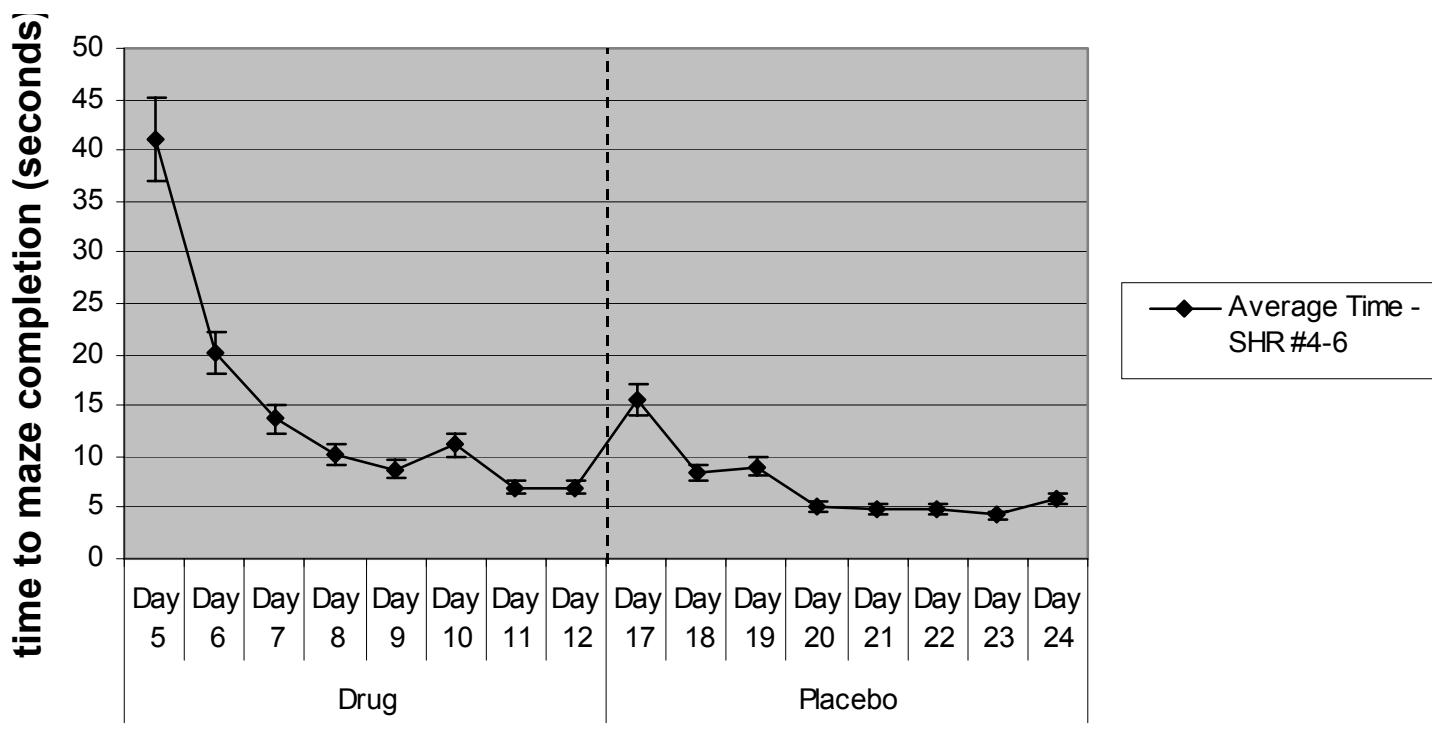

Figure 1. Time to Morris Water Maze completion: SHR (1-3) and SHR (4-6)

The graphs in Figure 2 also show that the effects of d-MPH on exploratory behavior are more pronounced in WKY rats as compared with the SHR rats. These results confirm earlier experiments that lead to the same conclusion but also lead to a new possibility $[4,13]$. The SPSS was run using data from the last three days of testing period one and the first three days of testing period two. For example, the last three days of maze testing while the SHRs 1-3 were under the influence of the drug was compared to the first three days while these rats were switched over to receiving the 
Average time per day to Morris Water Maze completion for WKY 7-9

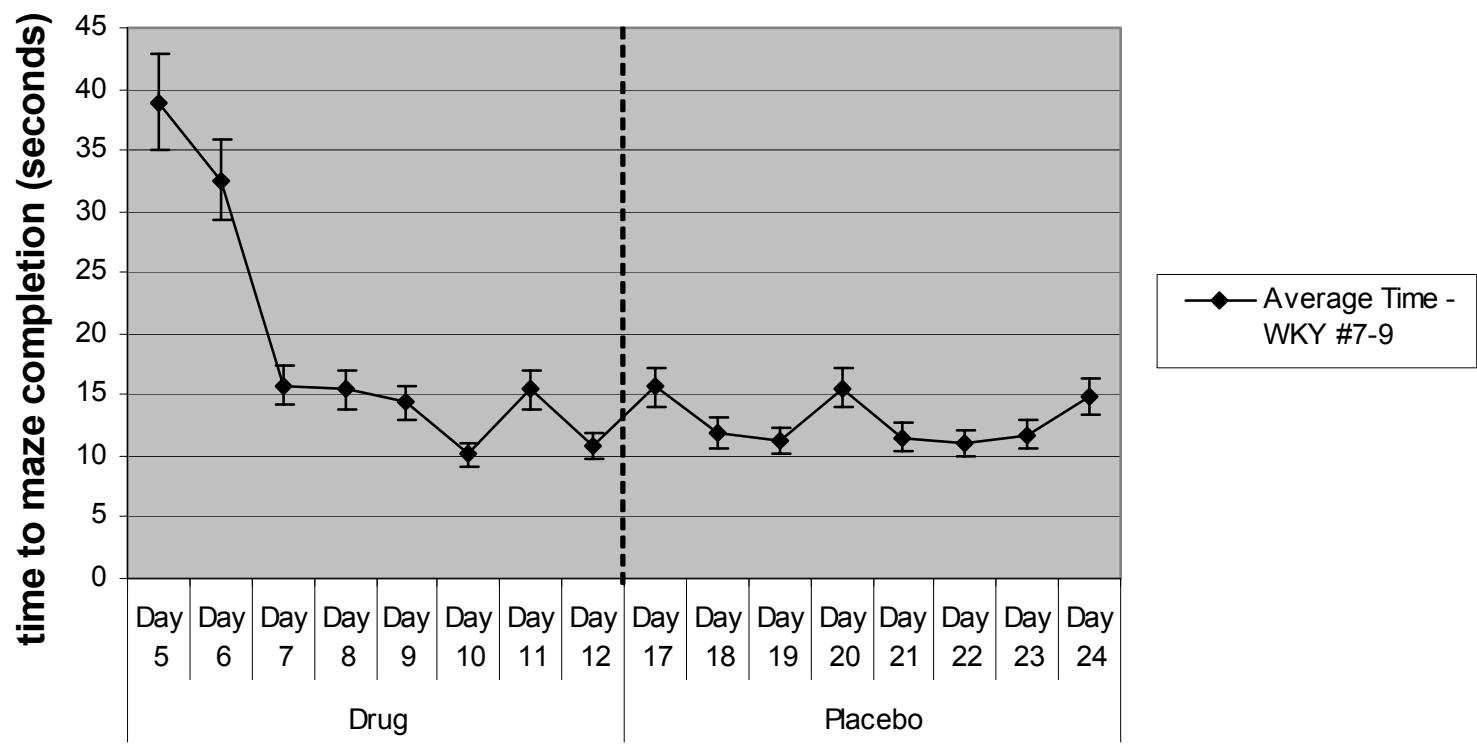

Average time to Morris Water Maze completion per day for WKY 10-12

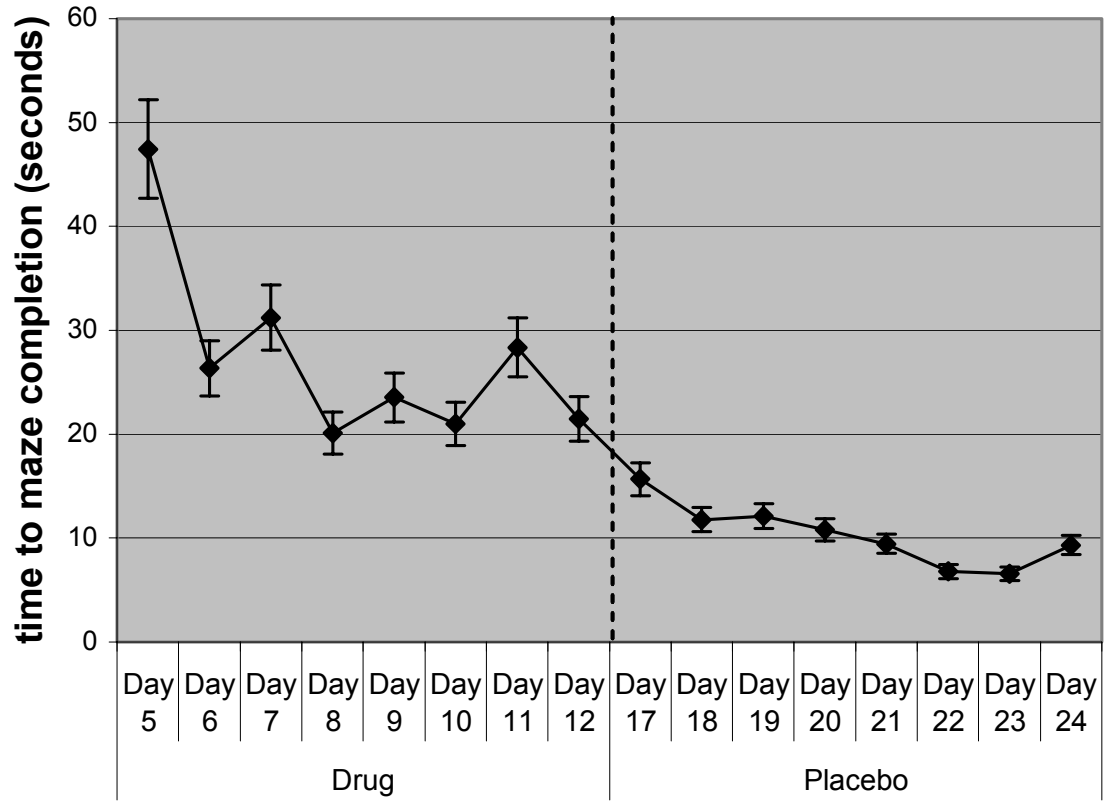

Figure 2. Time to Morris Water Maze completion: WKY (7-9) and WKY (10-12)

placebo. This was done to examine whether switching to the drug or placebo for each group of rats caused a disruption in their performance of the maze. According to tests of significance run by SPSS, the variability of performance increased for all of the rats when they received the placebo first and the drug second, and the variability went down when the rats received the drug first and the placebo second. This indicates 
that the drug did disrupt the performance of all of the rats to some extent. The degree to which the drug affected each strain of rats can also be examined using this data. When comparing the two groups of rats, the variability appears to be higher for the WKY rats but the statistical evidence narrowly negates this statement. According to SPSS, the WKYs were not more affected by the drug because the probability that the data generated due to chance regarding this topic is 0.059 which is not less than the established highest probability of 0.05 $(\underline{F}(1,8)=4.82, \underline{p}=0.059)$. However, due to the very narrow margin that this statement is rejected and the fact that the performance of both strains was slightly disrupted in this task through the administration of MPH calls for further investigation over a longer time with a larger sample size.

\section{b. Growth}

This study found no significant difference among the growth rates of the rats due to the administration of d-MPH or the placebo (Figure 3) and confirms earlier experiments in this area [14]. Each rat maintained a positive growth rate overall and showed no hindrance in weight gain following administration of d-MPH. Continuing the examination of this parameter with a larger sample size would yield more reliable results. Also, continuing the experiment until the rats have completed growth would allow for the examination of whether overall growth is diminished.

\section{c. Blood Composition}

The blood glucose levels of the SHR and WKY rats in each group are presented in Figure 4. The mean values are consistent within each group $(101 \mathrm{mg} / \mathrm{dl}$ for the SHR rats and $202 \mathrm{mg} / \mathrm{dl}$ for the WKY rats). They are significantly different between strains however they closely follow the values suggested by Taconic (SHR $108.1 \mathrm{mg} / \mathrm{dl}$; WKY $203.1 \mathrm{mg} / \mathrm{dl}$ ) (Germantown, N.Y.). The slight differences may be due to outside factors such as diet, time of day, or instrumentation calibration error. It is safe to conclude that the administration of d-MPH does not lead to a direct change in blood glucose levels. In the same fashion values of blood $\mathrm{pH}$ were consistent for each animal throughout the experiment although a range of values (7.20-7.40) was found amongst rats in each strain. Thin layer chromatography experiments with isolated erythrocyte membranes were consistent for all animals and suggested similar overall composition and ratios of phosphatidyl serine, phosphatidyl choline, and phosphatidyl ethanolamine. In the constraints of this study it can be concluded that d-MPH has not been found to have an effect on blood glucose levels, blood $\mathrm{pH}$, and the composition of erythrocyte membranes.

The results of these experiments suggest that $d$-methylphenidate hydrochloride has little or no effect on blood glucose levels, blood $\mathrm{pH}$, and erythrocyte membrane composition as was expected. The hypothesis that the drug would hinder growth must be rejected however, due to the steady and unchanging growth rate of the subjects in this study. The final hypothesis concerning maze performance must also be rejected because the spontaneously hypertensive rats did not have improvement in maze performance after administration of the drug and the Wistar Kyoto rats were only slightly disrupted. However, there were some unexpected and interesting conclusions that came from the statistical maze analysis. Although slightly negated by the statistics, the WKYs did have more variability while under the influence of the drug and they were slower at completing the maze overall. The transition from placebo to drug also caused more of a disruption in maze completion ability in both strains than the transition from drug to placebo.

Further experimentation with a larger sample size and longer duration would be able to confirm the conclusions drawn here. Because the SHR and WKY rats are basically different in their spatial working memory abilities, it would also be helpful to examine another animal model of ADHD when testing these factors. It has even been suggested that the WKY is no longer an adequate control group for the SHR. While the SHR was originally selectively bred from the WKY, it is possible that these two rat strains have become too genetically distinct over time and can no longer serve as accurate comparisons [15]. Wistar Kyoto Hyperactive without hypertension (WKHA) rats may be a more 


\section{Average SHR and WKY Growth/Weight Chart}

\section{(in grams)}

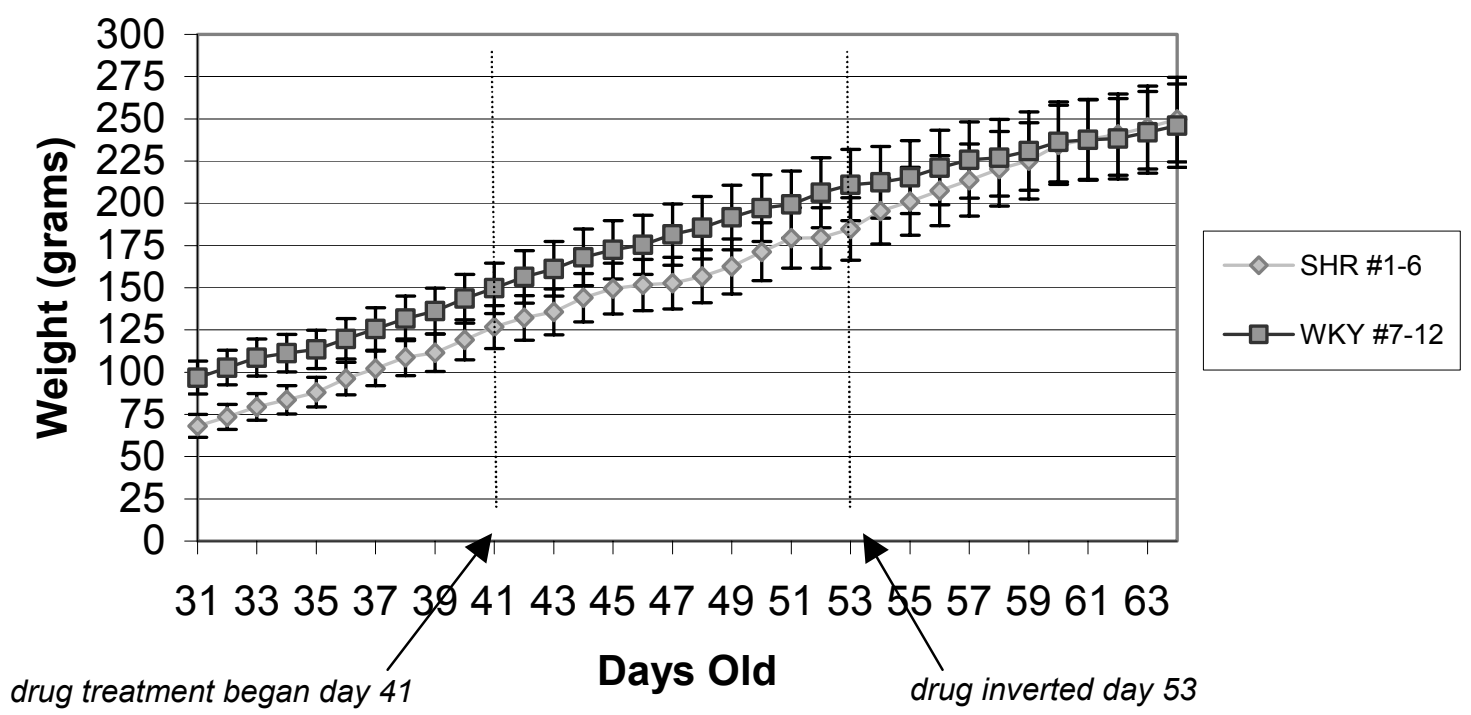

Figure 3. Average overall weight in grams of SHR and WKY rats plotted through preexperimental, testing period I and testing period II phases. All SHRs are averaged on one curve and all WKYs are averaged on the other curve.

\section{Blood Glucose Levels (mg/dl)}

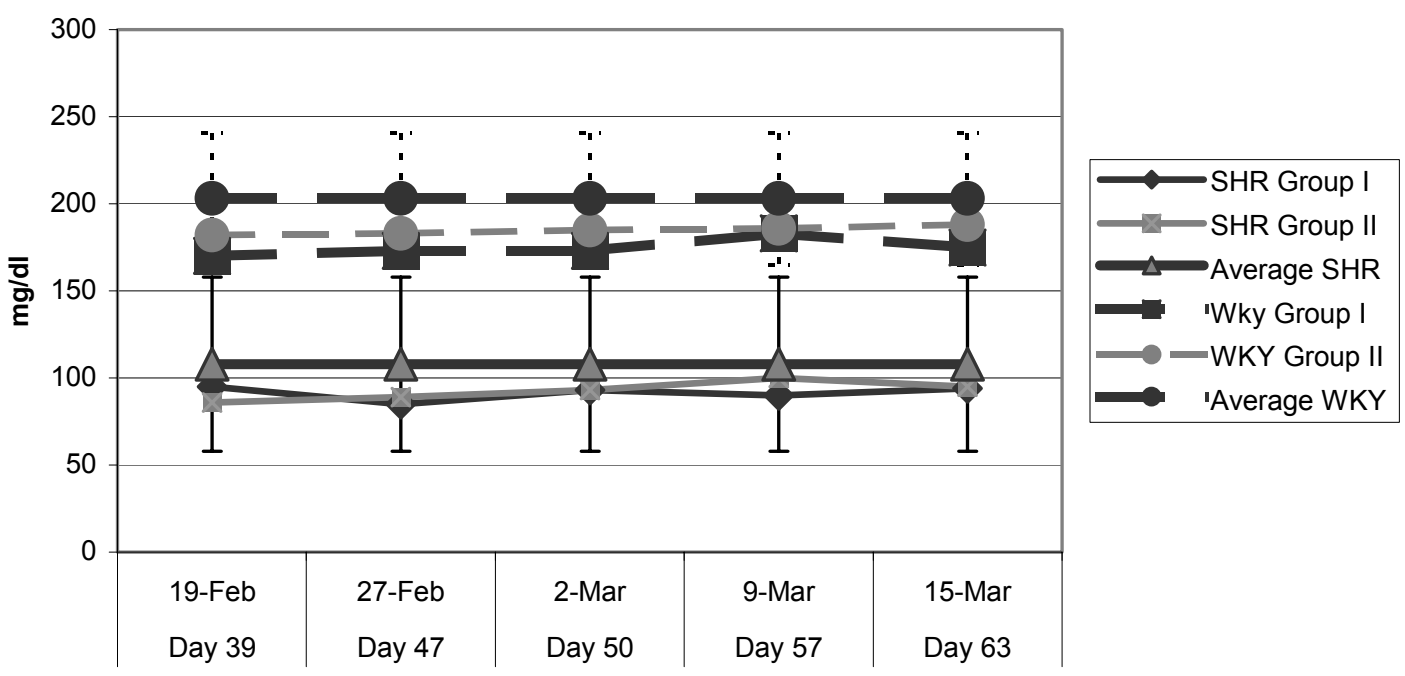

time period blood drawn

Figure 4. Blood Glucose levels ( $\mathrm{mg} / \mathrm{dl}$ ) for each strain for 5 days in pre-experimental (day 39), testing period I (days 47 and 50), and testing period II (days 57 and 63) phases. Each rat group, as well as empirically established averages for the two different strains, is plotted separately. 
pure experimental group and due to its recent development from the original Wistar Kyoto; it may not be too genetically distinct from this control group [15]. There are also other animal models such as Naples High/Low Excitability rats and knockout mice but neither of these groups has the established construct or predictive validity necessary to serve as an animal model of ADHD

While analysis of the maze performance data reveals significant differences due to drug administration, the physiological parameters of weight, blood $\mathrm{pH}$, erythrocyte membrane lipids, and blood glucose remained constant throughout the experiment. The stability of these characteristics is somewhat relieving because this drug is administered daily to millions of children in the United States. However, d-MPH does appear to cause changes in the behavioral and mental capacities of its subjects as suggested by this study.

\section{ACKNOWLEDGEMENTS}

Much appreciation and thanks is expressed to professors Jeanne Lust and Manuel Campos for their support and advice throughout the project. The authors would like to thank Elena Jelsing and especially Lauren Silus for their efforts in editing and reproducing the figures. This work was supported by a grant from Merck Pharmaceuticals and the American Association for the Advancement of Science.

\section{REFERENCES}

1. National Institute of Mental Health. www.nimh.gov/publicat/adhdqa.cfm
2. Diagnostic and Statistical Manual of Mental Disorders: DSM-IV-TR ${ }^{\mathrm{TM}}$ (2000). American Psychiatric Association: Washington, D.C.

3. Fine, Lisa. "Study: Minimum ADHD Incidence Is 7.5 Percent." www.edweek.org/ew/newstory.cfm?slug =28adhd.h21 (27 March 2002).

4. Sagvolden, T. (1998). www.mcmaster.ca/inabis98/sadile/sagv olden0567/two.html.

5. Zametkin, A. (1990). Section on Clinical Brain Imaging: Laboratory of Cerebral Metabolism. Division of Intramural Research Programs, NIMH.

6. Ingersoll, E. (2001). www.csuohio.edu/casal/berea.htm

7. Vastag, B. (2001). JAMA 286:905

8. Gauron, E.F., Rowley, V.N. (1975). Eur. J. Pharmacol. 347-350.

9. Arntzen, E. (1993). Psychol. Rec. 223233.

10. Morris, R.G.M. (1984). Development of a water-maze procedure for studying spatial learning in the rat. Journal of Neuroscience Methods 11:47-60.

11. Gasque, C. E. (1989). Laboratory Experiences in Molecular Biology. W.C. Brown Publishers.

12. Cenacchi. T., Bertoldin, T., Farina, C., Fiori, M.G., Crepaldi, G. (1993). Aging 5:123-133.

13. Wultz, B., Sagvolden, T., Moser, E.I., Moser, M.B. (1990). Behav. Neuro. Biol. 53:88-102.

14. Pizzi, W.J., Rode, E.C., Barnhart, J.E. (1987). Neurotoxicol. Teratol. 9:107-111.

15. Solanto, M.V., Arnsten, A.F.T., Castellanos, F.X., Stimulant Drugs and $A D H D$. (Oxford University Press, Oxford and New York, 2001).

\section{College of Saint Benedict}

Saint John's University 


\section{University of Northern lowa}

\section{Center for Energy and}

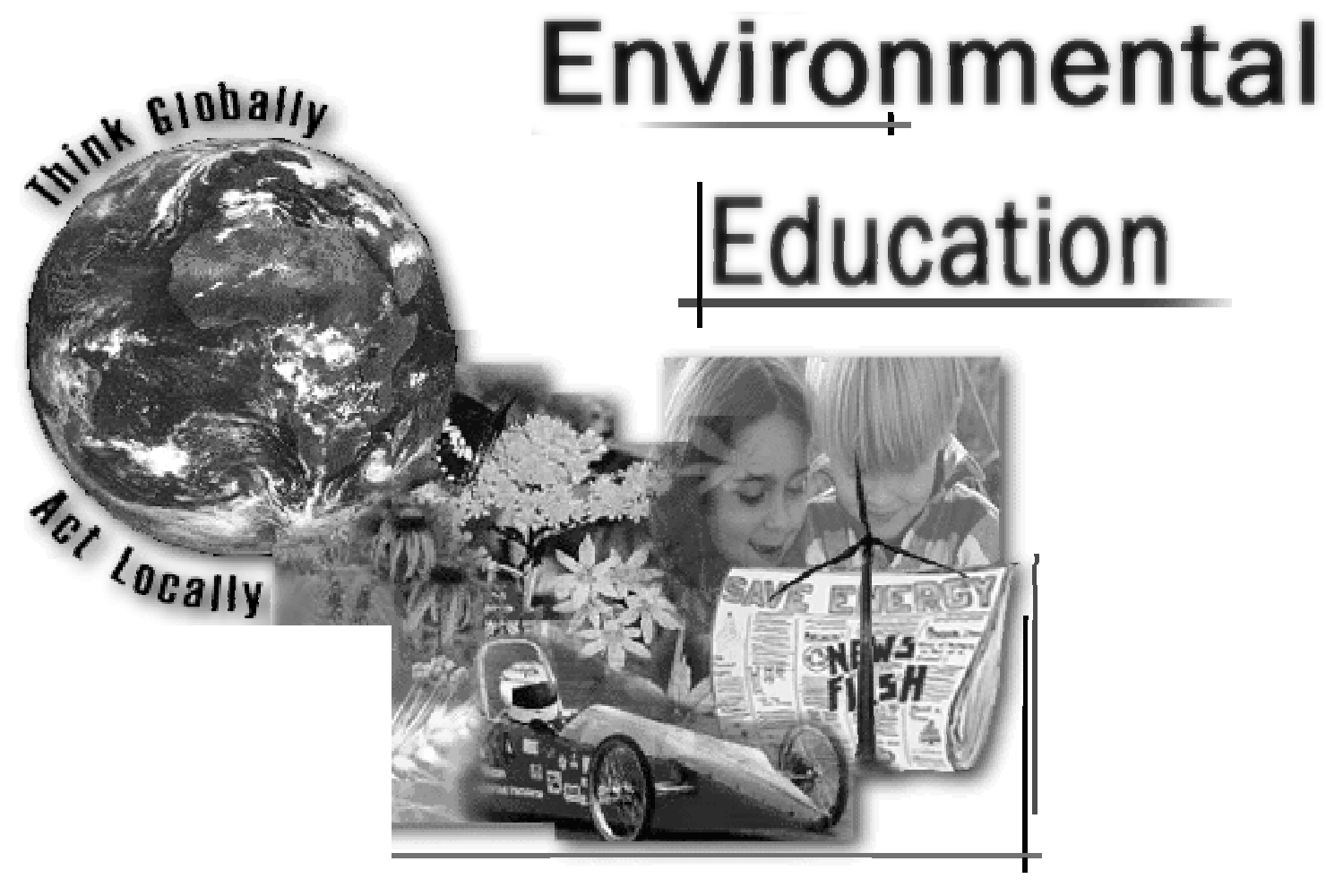

http://www.uni.edu/ceee/ 